\title{
BIOLOGICAL AND DOCKING STUDIES OF NOVEL AROYLHYDRAZONES
}

\author{
J. MANJULA ${ }^{\mathrm{a}}$, R. MAHESWARI \\ aPG and Research Department of Chemistry, Periyar EVR College, Tiruchirappalli, Tamilnadu, India, bDepartment of Chemistry, \\ Saranathan College of Engineering, Tiruchirappalli, Tamilnadu, India \\ Email: swaroopapranav@gmail.com
}

Received: 24 Jan 2017 Revised and Accepted: 09 Mar 2017

\begin{abstract}
Objective: Novel aroylhydrazone schiff bases were synthesized and were screened for their biological activities.

Methods: Using $\mathrm{HCl}$ as a catalyst, all the compounds were synthesized at room temperature and were characterized by IR and NMR techniques. The synthesized Schiff bases were screened for antibacterial, antifungal activities. In silico molecular docking, method was performed to study their antituberculosis activity against enoyl acyl carrier protein reductase (InhA) from Mycobacterium tuberculosis (PDB id: 2NSD).

Results: Compound P1 showed good antibacterial activity against gram positive (S. aureus) and gram negative (E. coli) bacterial strains and compound J1 showed good antifungal activity against A. niger. Molecular docking results reveal that compound B1 made two numbers of electrostatic interactions with 2NSD with more negative $\mathrm{C}$ docker interaction value. This indicated that the compound B1 was more active with minimum binding potential which is comparable with that of standard compound isoniazid.
\end{abstract}

Conclusion: Aroylhydrazones having good biologically activities compared to that of standards were prepared.

Keywords: 2,4,5-trifluorobenzaldehyde, DPPH, Tuberculosis, Molecular docking, InhA

(C) 2017 The Authors. Published by Innovare Academic Sciences Pvt Ltd. This is an open access article under the CC BY license (http://creativecommons.org/licenses/by/4.0/) DOI: http://dx.doi.org/10.22159/ijpps.2017v9i5.10862

\section{INTRODUCTION}

Tuberculosis (TB) "19th-century illness" could be a high communicable killer disease. In 2014, 9.6 million individuals fell sick with TB and 1.5 million died from the malady. Over ninety-fifth of TB deaths occur in low and middle-income countries, and it's among the highest five causes of death for women aged fifteen to forty-four. TB could be a leading killer of HIV-positive people: in 2015, one in three HIV deaths was because of TB. Globally in 2014, associate calculable 480000 individuals developed multidrug-resistant TB (MDR-TB). TB epidemic by 2030 is among the health targets of the recently adopted sustainable development goals [1].

Therefore, there's associate pressing got to develop new medicine against this world's most difficult public ill health. Drug discovery and development could be a complicated, time intense and a rich method [2]. It becomes still more expensive when the safety, efficacy and other issues are raised. In silico drug design, computational approach plays a significant role in all stages of drug development from the initial lead design to final stage clinical development [3]. Docking software is a valuable tool in pharmacy and medicine as most drugs are small molecules designed to interact with biologically relevant target proteins (receptors) in order to act on the biological pathway they are involved in.

The full therapeutic possibilities of hydrazides were realized after the discovery of isonicotinic acid hydrazide (INH) drugs which are in clinical practice for more than $50 \mathrm{y}$ [4]. Due to the presence of azomethine group $(>\mathrm{C}=\mathrm{N}-\mathrm{NH}-\mathrm{CO})$ hydrazones are considered as a special group of compounds and their industrial applications are vast [5]. Hydrazones are used as antimicrobial, antioxidant, antituberculosis, anticancer, antimalarial anti-inflammatory, antiplatelet diseases due to their interesting chemical and structural properties [6-12].

Keeping the various biological applications of hydrazones in mind and in continuation of our earlier research [13], in the present study we reported novel biologically active hydrazone shiff bases using 2,4,5-trifluorobenzaldehyde as a source of the carbonyl compound. The novelty of the present work resided in it's synthesize and molecular docking analysis. Drug discovery and development is a complex, lengthy and costly process, entrenched with a high degree of uncertainty that a drug will actually succeed. It becomes still more expensive when the safety, efficacy and other issues are raised. For faster development, nowadays almost every multi-national drug company and Contract Research Organization (CRO) involved in drug discovery has adopted computational methodology in different stages of the design process.

Many computational methods complement one another and may be combined to help rationalize the drug discovery process [14]. In this research, we attempted to find the anti-tubercular nature of synthesized compounds by virtual screening method. Virtual screening uses computational docking method and is used to predict the binding position and orientation of small molecules with active sites of pathogens. The crystal structure of pathogen available in Protein Data Bank could be used for docking studies.

\section{MATERIALS AND METHODS}

All anhydrous solvents and reagents of AR grade were obtained from commercial suppliers and used without any further purification unless otherwise noted. All the reactions were carried out at room temperature. Melting points were determined by open capillary and are uncorrected. FT-IR spectral measurements were recorded using Perkin Elmer Spectrum-1 FT-IR spectrometer in 4000-400 $\mathrm{cm}^{-1}$. NMR was recorded with Bruker NMR spectrometers operating at $400 \mathrm{MHz}$ for ${ }^{1} \mathrm{H}$ and $100 \mathrm{MHz}$ for ${ }^{13} \mathrm{CNMR}$. DMSO- $\mathrm{d}_{6}$ was used as a solvent and TMS as an internal reference.

\section{Synthesis}

To the ethanolic solution of benzo hydrazide (0.1 mol), 2,4,5trifluorobenzaldehyde $(0.1 \mathrm{~mol})$ and few drops of con $\mathrm{HCl}$ were added. The reaction mixture was stirred well at room temperature for $30 \mathrm{~min}$. Insoluble solid gradually generated was filtered and washed with petroleum ether(40-60\%) and dried in vacuum desicator. The crude solid was recrystallised from absolute ethanol. Similar reaction and purification procedures were applied to prepare all the compounds. 
<smiles>[R]c1ccc(C(=O)NN)cc1</smiles><smiles>O=Cc1cc(F)c(F)cc1F</smiles>

\section{$\mathrm{C}_{2} \mathrm{H}_{5} \mathrm{OH} / \mathrm{Con} . \mathrm{Hcl}$}

$\mathrm{R} 1=-\mathrm{H},-\mathrm{Cl},-\mathrm{OMe}$<smiles>[R8]c1ccc(C(=O)N/N=C/c2cc(F)c(F)cc2F)cc1</smiles>

or the synthesis of aroylhydrazone schiff bases

\section{Determination of antimicrobial activity}

The antimicrobial activities of synthesized compounds were screened against grampositive bacteria ( Staphylococcus aureus), gram-negative (Escherichia coli) and fungi (Aspergillus niger) strains by agar well diffusion method [15] at a concentration level of $100 \mu \mathrm{g} / \mathrm{ml}$. The microorganisms used were obtained, identified and confirmed by Microbiologists, Department of Microbiology, Thanjavur Medical College, Thanjavur. Nutrient agar was used as culture media and DMSO was used as a solvent. Standard sterilized filter paper disks ( $5 \mathrm{~mm}$ diameter) impregnated with a solution of the test compound in DMSO $(1 \mathrm{mg} / \mathrm{ml})$ was placed on agar plate seeded with the appropriate test organism in triplicates. The Petri plates were incubated at $37^{\circ} \mathrm{C}$ for $24 \mathrm{~h}$ for bacterial strains and $48 \mathrm{~h}$ for fungi. After incubation, the plates were observed for the zone of inhibition. The Antimicrobial activities of synthesized compound were compared with Erythromycin and Gentamycin as standard. Each sample was tested in triplicate.

\section{Molecular docking studies}

Molecular docking studies were performed using accelrys discovery studio software program. The target protein enoyl acyl carrier protein reductase (InhA) from Mycobacterium tuberculosis (PDB ID2NSD) was downloaded from protein data bank and the active site was chosen. It was processed by the addition of hydrogen, assigning the bond order, identifying overlaps, creating zero-order bonds to metals and creating disulphide bonds. The co-factors, unwanted water molecules and chains were deleted. Then energy minimization was done followed by grid generation. The designed ligands were saved as mol format and were examined so as to generate the best pose by analyzing the binding interactions. The scoring functions and hydrogen bonds formed with the surrounding amino acids are used to predict their binding modes, their binding affinities and orientation of these compounds at the active site A of 2NSD.

\section{RESULTS AND DISCUSSION}

Aroylhydrazide derivatives were synthesized via condensation reaction by Schiff base route. All the products were immiscible in polar solvents and soluble with DMSO and DMF. The postulated structures of the newly synthesized compounds (table 1) were in good agreement with their FT-IR, ${ }^{1} \mathrm{H}$ NMR and ${ }^{13} \mathrm{C}$ NMR spectral data.

(E)-N'-(2,4,5-triflorobenzylidene)benzohydrazide (B1) was derived from benzohydrazide and 2,4,5-triflorobenzaldehyde (1:1) Yield: 96\%. FT-IR: ( $v$ in $\mathrm{cm}^{-1}$ ) 3409(NH), 3069(Ar-CH), 2848(Ali-CH), 1645(CO). ${ }^{1} \mathrm{H}$ NMR $\delta$ in ppm (400 MHz, DMSO-d 6 ): 12.1 (s, $1 \mathrm{H}$, enolic $\mathrm{NH}), 8.7(\mathrm{~s}, 1 \mathrm{H}, \mathrm{CH}=\mathrm{N}), 7.9-7.5(\mathrm{~m}, 7 \mathrm{H}, \mathrm{Ar}-\mathrm{H}) .{ }^{13} \mathrm{C}$ NMR $\delta$ in ppm $(100$ MHz, DMSO-d $\left.{ }_{6}\right)$ 163(CO), 138(C=N), 133, 132, 128, 127, 119, 113, 107, 106(Ar-C).

(E)-4-chloro- $N$ '-((2,4,5-triflorobenzylidene)benzohydrazide (P1) was derived from 4-chloro benzohydrazide and 2,4,5-triflorobenzaldehyde. (1:1) Yield: 97\%. FT-IR: $\left(v\right.$ in $\left.\mathrm{cm}^{-1}\right)$ 3475(NH), 3059(Ar-CH), 2850(Ali-CH), 1616(CO). ${ }^{1} \mathrm{H}$ NMR $\delta$ in ppm $(400 \mathrm{MHz}$, DMSO- $\left._{6}\right): 11.9(\mathrm{~s}, 1 \mathrm{H}$, enolic $\mathrm{NH}), 8.6(\mathrm{~s}, 1 \mathrm{H}, \mathrm{CH}=\mathrm{N}), 7.9(\mathrm{~d}, 2 \mathrm{H}, \mathrm{o}-$ ArCl), 7.8(s, $1 \mathrm{H}, \mathrm{o}-\mathrm{ArF}), 7.7(\mathrm{~s}, 1 \mathrm{H}, \mathrm{m}-\mathrm{ArF}), 7.0(\mathrm{~d}, 2 \mathrm{H}, \mathrm{m}-\mathrm{ArCl}) \cdot{ }^{13} \mathrm{C}$ NMR $\delta$ in ppm (100 MHz, DMSO-d 6 ) 162(CO), 157(C=N), 154, 152, $148,145,144,137,129,124,119,113,107,106($ Ar-C).

(E)-4-methoxy- $N$ '-((2,4,5-triflorobenzylidene $)$ benzohydrazide (J1) was derived from 4-methoxy benzohydrazide and 2,4,5triflorobenzaldehyde (1:1) Yield: 98\%. FT-IR: $(v$ in $\mathrm{cm}-1)$ 3474(NH), 3059(Ar-CH), 2849(Ali-CH), 1617(CO). 1H NMR $\delta$ in ppm (400 MHz, DMSO-d6): 11.9(s, $1 \mathrm{H}$, enolic $\mathrm{NH}), 8.6(\mathrm{~s}, 1 \mathrm{H}$, $\mathrm{CH}=\mathrm{N}), 7.9(\mathrm{~d}, 2 \mathrm{H}, \mathrm{o}-\mathrm{ArOMe}), 7.8(\mathrm{~s}, 1 \mathrm{H}, \mathrm{o}-\mathrm{ArF}), 7.7(\mathrm{~s}, 1 \mathrm{H}, \mathrm{m}-\mathrm{ArF})$, 7.1(d, 2H, m-ArOMe). 13C NMR $\delta$ in ppm $(100 \mathrm{MHz}$, DMSO-d6) 162(CO), 157(C=N), 154, 152, 151, 148, 145, 137, 129, 119, 113, 107, 106(Ar-C), 55(OMe).

\section{Antimicrobial activity}

The antimicrobial activities of synthesized compounds were given in table 1 . All the compounds show better activity against $S$. aureus and A. niger. At the same time, activity against E. coli was found to be less for all the three compounds. In short, P1 shows comparatively greater anti-bacterial activity and J1 shows good anti-fungal activity.

Table 1: Antimicrobial activities of aroylhydrazones

\begin{tabular}{llll}
\hline Compound id & Zone of inhibhition (mm) & \\
\cline { 2 - 4 } & S. aureus & E. coli & \multicolumn{1}{l}{ A. niger } \\
\hline B1 & $12 \pm 0.81$ & $11 \pm 0.19$ & $11 \pm 0.13$ \\
J1 & $22 \pm 0.41$ & $17 \pm 0.25$ & $13 \pm 0.16$ \\
P1 & $18 \pm 0.62$ & $14 \pm 0.32$ & $16 \pm 0.14$ \\
Erythromycin & $28 \pm 0.31$ & $23 \pm 0.09$ & $25 \pm 0.14$ \\
Gentamycin & $16 \pm 0.37$ & $22 \pm 0.22$ & $14 \pm 0.21$ \\
\hline
\end{tabular}

While comparing the presence of substituents in the aromatic ring of hydrazides, the presence of electron donating group enhanced the antimicrobial activities whereas the presence of electron withdrawing group significantly reduced the activities [16].

\section{Molecular docking}

In order to find a suitable inhibitor for Mycobacterium tuberculosis, InhA docking study was carried out. InhA catalyzes the reduction of long-chain trans-2-enoyl-ACP in the type II fatty acid biosynthesis pathway of $M$. tuberculosis. Inhibition of InhA disrupts the biosynthesis of the mycolic acids that are central constituents of the mycobacterial cell wall. The docking scores were shown in table 2.

The types and number of interactions between the synthesized aroylhydrazones and Mycobacterium tuberculosis InhA were shown in fig. 1-4. The more negative value of Cdocker interaction energy indicates the good binding potential or the more antituberculosis activity against Mycobacterium tuberculosis InhA protein. 


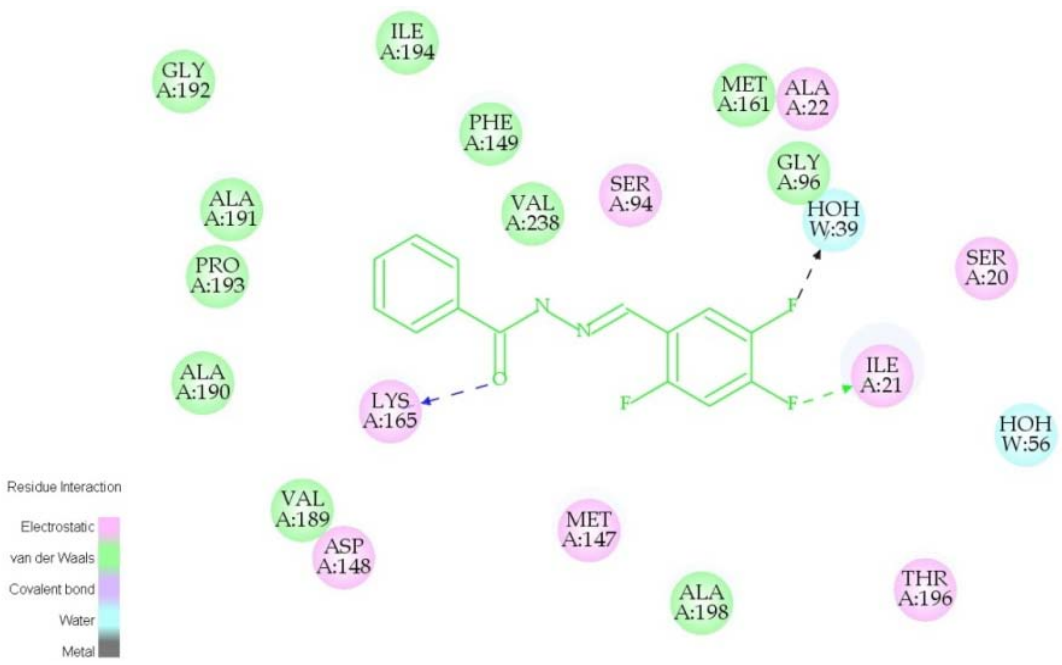

Fig. 1: Binding configuration of B1 with 2NSD

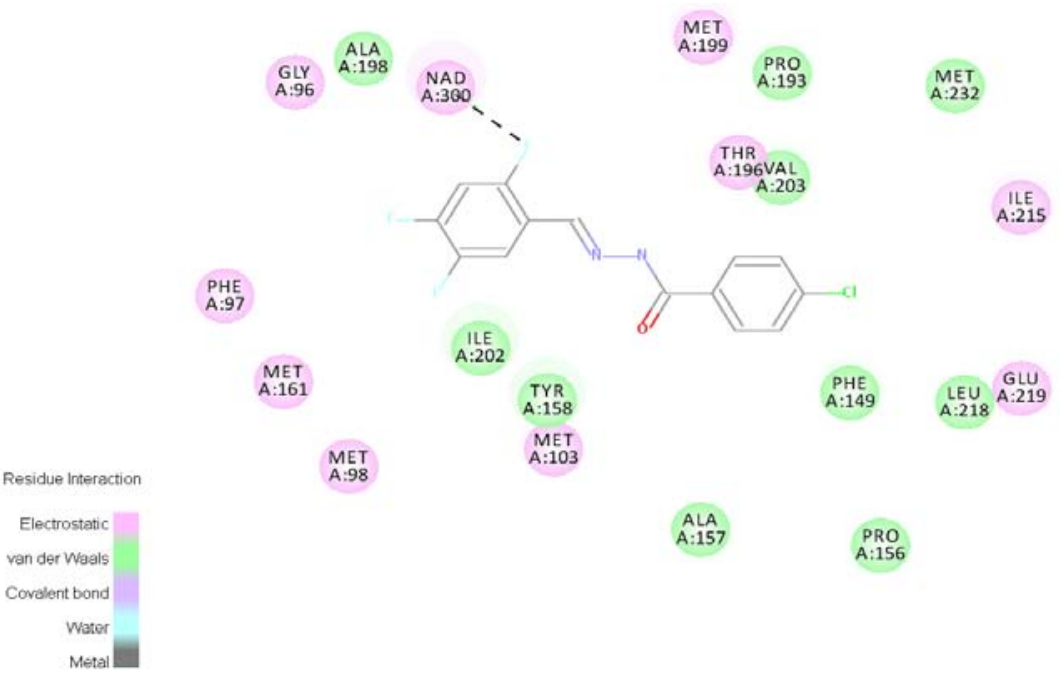

Fig. 2: Binding configuration of P1 with 2NSD

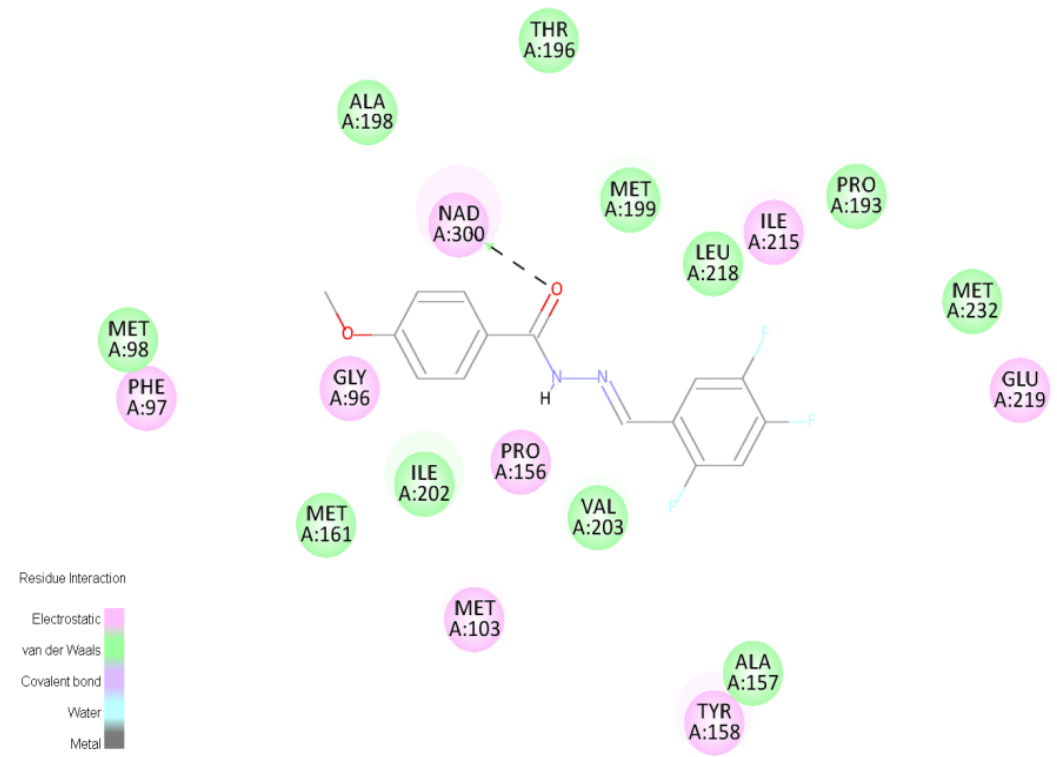

Fig. 3: Binding configuration of J1 with 2NSD 


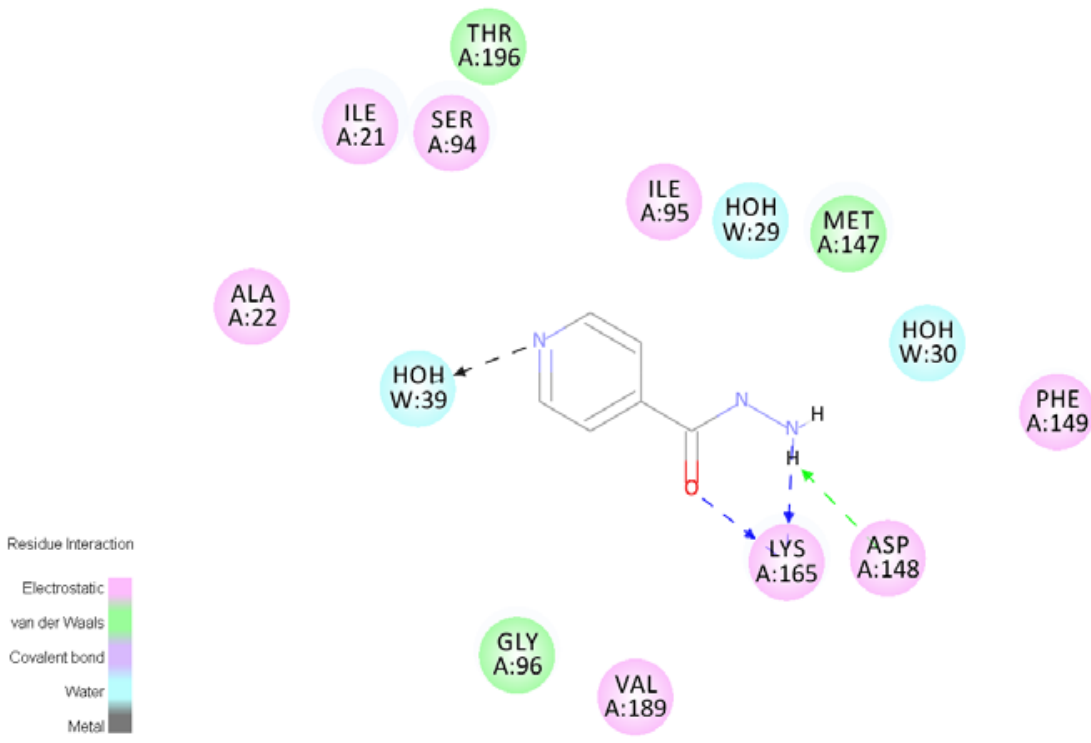

Fig. 4: Binding configuration of isoniazid with 2NSD

Table 2: Statistical docking results of the aroylhydrazones [ADS version 2.5 software]

\begin{tabular}{|c|c|c|c|c|c|c|c|}
\hline Compound id & $\begin{array}{l}\text { Potential } \\
\text { energy }\end{array}$ & $\begin{array}{l}\text { Van der walls } \\
\text { energy }\end{array}$ & $\begin{array}{l}\text { Electrostatic } \\
\text { energy }\end{array}$ & $\begin{array}{l}\text { Initial RMS } \\
\text { gradient }\end{array}$ & $\begin{array}{l}\text { Final RMS } \\
\text { gradient }\end{array}$ & $\begin{array}{l}\text { CDocker } \\
\text { energy }\end{array}$ & $\begin{array}{l}\text { CDocker } \\
\text { interaction energy }\end{array}$ \\
\hline B1 & 13.15033 & 3.12177 & 1.32932 & 43.22383 & 0.09303 & -22.9303 & -37.3152 \\
\hline P1 & 11.98248 & 3.60418 & -2.98297 & 41.26503 & 0.09358 & -27.9953 & -40.7347 \\
\hline $\mathrm{J} 1$ & 14.03885 & 2.92098 & 1.03532 & 43.24664 & 0.08363 & -29.6707 & -44.3367 \\
\hline $\begin{array}{l}\text { Isoniazid } \\
\text { (standard) }\end{array}$ & -6.67385 & 1.78410 & -11.80107 & 42.51513 & 0.07183 & -22.1896 & -27.3771 \\
\hline
\end{tabular}

Table 3: Molecular interactions of aroylhydrazones with active site residues of 2NSD

\begin{tabular}{|c|c|c|c|}
\hline \multirow[t]{2}{*}{ Compound id } & \multicolumn{3}{|c|}{ Interaction details } \\
\hline & Type & Number & Residues involved \\
\hline B1 & Electrostatic & 2 & $\begin{array}{l}\text { (1) Between-C=0-of benzo hydrazide and of amino acid residue LYS A: } 165 \\
\text { (2) Between fluorine of aldehyde and of amino acid residue ILE A: } 21\end{array}$ \\
\hline $\mathrm{J} 1$ & Electrostatic & 1 & Between fluorine of aldehyde and NAD 300 of amino acid residue \\
\hline P1 & Electrostatic & 1 & Between-C=0-of benzo hydrazide and NAD 300 of amino acid residue \\
\hline Isoniazid & Electrostatic & 2 & $\begin{array}{l}\text { (1) Between-C=0-of benzo hydrazide and and of amino acid residue LYS A: } 165 \\
\text { (2) Between hydrogen of benzohdrazide and LYS A: } 165 \text { of amino acid residue }\end{array}$ \\
\hline & Van der Walls & 1 & Between hydrogen of benzohydrazide and of amino acid residue ASP: 148 \\
\hline
\end{tabular}

From the results of docking, it was found that CDocker score of compound B1 was more negative. This implied that B1 needed only less energy to bind with the active site of the pathogen. At the same time, it made two numbers of electrostatic interactions with amino acid residue LYS A: 165 which was comparable with that of standard drug isoniazid. Therefore compound B1may be suitable to overcome the drug resistance of enoyl acyl carrier protein reductase (InhA) from Mycobacterium tuberculosis.

\section{CONCLUSION}

Novel aroylhydrazones were synthesised using the simple and convenient method. The antimicrobial activities of the synthesized compounds screened against gram positive $S$. aureus and gramnegative $E$. coli bacterial and $A$. niger fungi strains reveals that all the compounds may acts as a potential antimicrobial activity. To expand the knowledge about anti-tuberculosis activity against Mycobacterium tuberculosis InhA, molecular docking study was performed. Compound B1 shows good binding ability with two electrostatic interactions, which is comparable with that of isoiazid, standard drug. Therefore, B1 was found to possess the good inhibitory capability and it may be suitable to overcome the drug resistance of Mycobacterium tuberculosis InhA protein.

\section{ACKNOWLEDGEMENT}

The authors express their thanks to the authorities of Government Arts College, Tiruchirappalli and Saranathan College of Engineering, Tiruchirappalli for providing laboratory facilities.

\section{CONFLICTS OF INTERESTS}

All authors have none to declare

\section{REFERENCES}

1. World Health Organization: Tuberculosis Fact sheet $\mathrm{N}^{\circ} 104$; 2015. Available from: http://www.who.int/mediacentre/ factsheets/fs104/en/. [Last accessed on 24 Dec 2015]

2. Dickson M, Gagnon JP. Key factors in the rising cost of new drug discovery and development. Nat Rev Drug Discovery 2004;3:417-29.

3. Md Mofizur Rahman, Md Rezaul Karim, Md Qamrul Ahsan, Abul Bashar Ripon Khalipha, Mohammed Raihan Chowdhury, Md Saifuzzaman. Use of computer in drug design and drug discovery: a review. Int J Pharm Life Sci 2012;1:1-21.

4. Fox HH. The chemical approach to the control of tuberculosis. J Org 1952;116:129-34.

5. Kiomars Zargoosh, Hossein Habibi, Amir Abdolmaleki, Kourosh Firouz. Synthesis of a polyamic hydrazide and its 
application for removal of heavy metal ions from industrial wastes. Iran Polym J 2015;24:561-71.

6. Pieczonka Adam M, Aleksandra Strzelczyk, Beata Sadowska, Grzegorz Mlostoń, Paweł Stączek. Synthesis and evaluation of antimicrobial activity of hydrazones derived from 3-oxido- $1 \mathrm{H}$ imidazole-4-carbohydrazides. Eur J Med Chem 2013;64:389-95.

7. Abdel-Wahab FB, Awad AEG, Badria AF. Synthesis, antimicrobial, antioxidant, anti-hemolytic and cytotoxic evaluation of new imidazole-based heterocycles. Eur J Med Chem 2011;46:1505-11.

8. Raja AS, Agarwal AK, Mahajan N, Pandeya SN, Ananthan A. Antibacterial and antitubercular activity of some diphenyl hydrazone and semicarbazone. Indian J Chem 2010;49B:1384-8.

9. Zheng LW, Wu LL, Zhao BX, Dong WL, Miao JY. Synthesis of novel substituted pyrazole-5-carbohydrazide hydrazone derivatives and discovery of a potent apoptosis inducer in A549 lung cancer cells. Bioorg Med Chem 2009;17:1957-62.

10. Walcourt A, Loyevsky M, Lovejoy DB, Gordeuk VR, Richardson DR. Novel aroylhydrazone and thiosemicarbazone iron chelators with anti-malarial activity against chloroquineresistant and sensitive parasites. Int J Biochem Cell Biol 2004;36:401-7.
11. Khan SA, Pooja M, Shabir P, Darpan K. Hydrazone derivatives of quinoxalinone as antimicrobial and anti-inflammatory agents. Acta Pol Pharm 2009;66:169-72.

12. Silva GA, Costa LMM, Brito FCF, Miranda ALP, Barreiro EJ, Fraga CAM. New class of potent antinociceptive and antiplatelet $10 \mathrm{H}$-phenothiazine-1-acylhydrazone derivatives. Bioorg Med Chem 2004;12:3149-58.

13. Maheswari R, Manjula J. Synthesis, characterization and biological applications of benzo hydrazide derivatives. Int J Appl Res 2015;1:587-92.

14. DiMasi JA, Hansen RW, Grabowski HG. The price of innovation: new estimates of drug development costs. J Health Econ 2003;22:151-85.

15. Okeke MI, Iroegbu CU, Eze EN, Okoli AS, Esimone CO. Evaluation of extracts of the root of Landolphia owerrience for antibacterial activity. J Ethnopharmacol 2001;78:119-2.

16. Duganath N, Sridhar C Jayaveera KN. Synthesis and antibacterial evaluation of some novel hesperidin semisynthetic derivatives. Der Pharm Lett 2014;6:87-94.

\section{How to cite this article}

- J Manjula, R Maheswari. Biological and docking studies of novel aroylhydrazones. Int J Pharm Pharm Sci 2017;9(5):81-85. 